\title{
Analisis Kekuatan Impact Komposit Polyester-Serat Tapis Kelapa Dengan Variasi Panjang Dan Fraksi Volume Serat Yang Diberi Perlakuan NaOH
}

\author{
I Putu Lokantara* \\ *Dosen Jurusan Teknik Mesin, Fakultas Teknik, Universitas Udayana \\ Kampus Bukit Jimbaran, Bali, Indonesia
}

\begin{abstract}
Abstrak
Tujuan penelitian ini adalah untuk menganalisis kekuatan impact komposit polyester berpenguat serat tapis kelapa yang diberi perlakuan $\mathrm{NaOH}$ pada panjang dan fraksi volume serat yang bervariasi

Komposit yang dibuat menggunakan penguat serat tapis kelapa dengan matrik berupa resin unsaturated polyester (UPRs) jenis Yukalac 157 BQTN-EX dengan 1\% hardener jenis MEKPO dengan variasi panjang serat tapis kelapa $5 \mathrm{~mm}, 10 \mathrm{~mm}$ dan $15 \mathrm{~mm}$ sedangkan variasi fraksi volume serat 20\%, 25\%, 30\%. Komposit dibuat dengan teknik press hand lay-up dengan perlakuan serat menggunakan campuran NaOH-Air. Perlakuan serat tapis kelapa dengan direndam di air mendidih dengan suhu $100{ }^{\circ} \mathrm{C}$ selama 1 jam, selanjutnya serat tapis kelapa dikeringkan menggunakan oven dengan suhu $65{ }^{\circ} \mathrm{C}$ selama 12 jam setelah itu serat tapis kelapa direndam didalam larutan $\mathrm{NaOH}$ - Air (5 gram $\mathrm{NaOH}+95 \mathrm{ml}$ air) selama 2 Jam. Komposit selanjutnya di post curing selama 12 jam dengan suhu $65^{\circ} \mathrm{C}$. Spesimen uji komposit dipotong sesuai standar ASTM D 256 untuk spesimen uji impact. Selanjutnya spesimen komposit dilakukan pengujian impact.

Kekuatan impact meningkat seiring meningkatnya fraksi volume dan panjang serat. Nilai kekuatan impact terbesar terdapat pada pengujian impact dengan komposit panjang serat $15 \mathrm{~mm}$ dengan Fraksi Volume $30 \%$ sebesar $0.0255 \mathrm{Nm} / \mathrm{mm}^{2}$. Hasil pengamatan struktur mikro menunjukkan bahwa pada panjang serat $15 \mathrm{~mm}$ ikatan antara matrik dan serat lebih kuat dibandingkan dengan variasi panjang serat $5 \mathrm{~mm}$ dan $10 \mathrm{~mm}$ sehingga komposit yang dihasilkan lebih kuat dan mempunyai nilai kekuatan impact yang lebih besar. Semakin panjang serat yang digunakan akan mengurangi crack deflection sehingga kekuatan impact menjadi semakin baik. Demikian pula dengan fraksi volume yang semakin tinggi menyebabkan matrix flow berkurang sehingga kekuatan impact akan meningkat.
\end{abstract}

Keywords: Kekuatan Impact, Fraksi Volume Serat, Panjang Serat, matrix flow

\section{PENDAHULUAN}

Komposit adalah suatu material yang terbentuk dari kombinasi dua atau lebih material, dimana sifat mekanik dari material pembentuknya berbeda-beda dimana satu material sebagai fasa pengisi (matrik) dan yang lainnya sebagai fasa penguat (reinforcement). Pemanfaatan bahan komposit sebagai bahan alternatif pengganti bahan logam dalam bidang rekayasa semakin meluas. Hal ini disebabkan karena keuntungan yang dimiliki oleh bahan komposit berpenguat serat alami seperti konstruksi menjadi lebih ringan, tahan korosi, dan kekuatannya dapat didesain sesuai dengan arah pembebanan. Penggunaan serat alami untuk bahan penguat pada komposit saat ini sedang berkembang dengan pesat. Serat alami memiliki banyak keunggulan dibandingkan dengan serat sintetis antara lain ringan, dapat didaur ulang, dapat terurai oleh bakteri pembusuk, dapat diperbaharui dan mempunyai kekuatan serta kekakuan yang relatif tinggi. Dalam penelitian ini akan diteliti bahan komposit polymer dengan berpenguat serat tapis kelapa. Dipilihnya serat tapis kelapa sebagai penguat karena serat tapis kelapa kurang mendapat perhatian dan jumlahnya berlimpah ruah sehingga dapat mengangkat derajat bahan limbah tersebut menjadi bahan bernilai teknis dan ekonomis yang lebih tinggi.

Penelitian pendahuluan yang telah dilakukan tentang komposit berpenguat serat alami adalah penelitian komposit polyester dengan penguat serat tapis kelapa dengan panjang serat 10 mm yang diberi perlakuan alkali $\mathrm{NaOH} 5 \%$ selama 2 jam didapat hasil untuk kekuatan bending tertinggi sebesar $125,98 \mathrm{Mpa}^{[1]}$, dan penelitian komposit polyester berpenguat serat tapis kelapa yang diberi perlakuan $5 \% \mathrm{NaOH}$ selama 2 jam dan fraksi volume $12,2 \%$ dengan perlakuan perendaman komposit ke dalam air pada suhu ruangan untuk mengetahui pengaruh penyerapan air terhadap kekuatan bendingnya dimana kekuatan bending komposit polyester tapis kelapa mengalami peningkatan hingga perendaman 24 jam yaitu sebesar 41,4\% dibandingkan dengan sebelum direndam $^{[2]}$

Dari latar belakang diatas maka perlu untuk melakukan penelitian pengaruh variasi panjang serat tapis kelapa dan fraksi volume serat terhadap kekuatan impact komposit tersebut. Hal ini diteliti untuk mengetahui panjang serat dan fraksi volume serat yang optimal yang mampu menghasilkan kekuatan impact maksimum,. 


\section{METODOLOGI}

\section{Alat dan Bahan Penelitian}

\subsection{Alat}

1. Alat uji : mesin uji lentur Leybold buatan Jerman. Alat Uji Impact (Charpy Type).

2. Alat cetak : alat cetak teknik Press Hand Lay-Up.

3. Alat ukur : Timbangan digital, gelas ukur, beker, neraca pegas, mistar, dan jangka sorong.

4. Alat pengering : oven.

5. Alat Keselamatan : sarung tangan karet dan masker.

6. Alat bantu : Gergaji, gunting, amplas, pisau, pengaduk, penjepit, sendok, selotip, kuas.

7. Alat pembersih : lap, kapi dan tinner.

\subsection{Langkah-Langkah Penelitian}

- Tapis Kelapa yang digunakan untuk pembuatan serat dipilih pada lapisan ketiga dari pelepah pohon, kemudian ujung tapis yang tipis dipotong untuk memudahkan memisahkan seratnya.

- Tapis kelapa dirobek-robek menjadi beberapa bagian kecil namun masih berupa lembaran serat. Setelah didapatkan serat tapis kelapanya, serat tapis kelapa dikeringkan dengan djemur disinar matahari. Serat kelapa yang telah kering dipotong dengan ukuran $5 \mathrm{~mm}, 10$ mm dan $15 \mathrm{~mm}$.

- Perlakuan serat tahap pretreatment pada serat tapis kelapa yaitu serat tapis kelapa direndam didalam air mendidih dengan suhu $100{ }^{\circ} \mathrm{C}$ selama 1 jam untuk menghilangkan kotoran atau getah yang masih menempel pada serat tapis kelapa $^{[2]}$

- Selanjutnya serat tapis kelapa dibersihkan dengan menggunakan air mengalir sampai air bilasan benar-benar bersih. Serat tapis kelapa yang telah bersih, selanjutnya keringkan serat tapis kelapa tersebut dengan cara masukan serat tapis kelapa ke dalam oven dengan suhu $65^{\circ} \mathrm{C}$ selama 12 jam $^{[2]}$.

- Perlakuan tahap treatment pada serat tapis kelapa yaitu serat tapis kelapa yang sudah dikeringkan tadi, lalu direndam didalam larutan zat kimia $\mathrm{NaOH}$ dengan air (5 gram $\mathrm{NaOH}$ dan $95 \mathrm{ml}$ air) selama 2 jam kemudian bilas dengan air sampai bersih $^{[1]}$.

\subsection{Bahan}

1. Matrik : Resin unsaturated polyester (UPRs) jenis Yukalac 157 $B Q T N$.

2 Reinforced: Serat tapis kelapa (Cocos Veridis) berukuran panjang $5 \mathrm{~mm}, 10$ $\mathrm{mm}$ dan $15 \mathrm{~mm}$.

3. Hardener ( pengeras) : Jenis Metil Etil Keton Peroxide jenis MEKPO.

4. Bahan perlakuan serat $: \mathrm{NaOH}$

5. Perekat / Lem G.

6. Selotip.

7. Gliserin.

8. Air mineral.

9. Aceton.

- Penentuan masa jenis serat dengan cara menimbang serat di udara dan menimbang serat dalam minyak tanah. Setelah diketahui masa jenis serat tapis maka dapat ditentukan berat komposit pada masing-masing fraksi volume yang diinginkan. Selanjutnya serat tapis kelapa siap diproses untuk menjadi komposit.

- Siapkan 2 bingkai kaca dengan ukuran $600 \times 600 \mathrm{~mm}$ dengan tebal $10 \mathrm{~mm}$ yang berfungsi sebagai landasan tempat cetakan komposit bagian bawah dan sebagai penutup cetakan bagian atas komposit.

- Siapkan 4 bilah kaca dengan ukuran 300 $\times 50 \times 3 \mathrm{~mm}$ yang berfungsi sebagai tempat cetakan untuk proses pembuatan komposit.

- Letakkan bingkai kaca dilantai yang datar, lalu tempelkan 4 bilah kaca dengan memakai lem $\mathrm{G}$, lalu beri tekanan pada bilah kaca yang dilem tadi sampai benar-benar kering.

- Cetakan kaca siap untuk dipakai dalam pembuatan komposit.

- Bersihkan cetakan dengan memakai air mengalir sampai bersih, setelah itu keringkan dan bersihkan memakai kain kering dan halus

- Cetakan komposit yang telah kering tadi dibersihkan lagi dengan memakai tinner A, baik untuk cetakan bagian bawah dan cetakan bagian atas sehingga cetakan kaca komposit tersebut bersih dengan 
sempurna. Biarkan beberapa saat hingga tinner mengering lalu bersihkan memakai kain kering.

- Gliserin dioleskan dengan setipis mungkin dipermukaan bingkai cetakan komposit baik untuk cetakan bagian bawah dan cetakan bagian atas, agar komposit setelah kering nanti tidak menempel pada cetakan

- Campurkan larutan matrik yaitu resin dengan hardener dengan persentase $1 \%$ hardener, jadi untuk penelitian ini dicampurkan larutan $990 \mathrm{ml}$ resin dengan $10 \mathrm{ml}$ katalis, dimana larutan tersebut diaduk hingga resin dan katalis tercampur dengan sempurna.

- Tuangkan setengah larutan resin dan katalis tersebut dicetakan kaca, rapikan dengan memakai kapi dan sendok. Tabur serat tapis kelapa dengan orientasi acak, serat tapis kelapa diatur agar dapat mengisi seluruh bagian dari cetakan komposit tersebut.

- Setelah serat tapis kelapa ditata dengan baik, selanjutnya tuangkan sisa larutan resin dan katalis tersebut dicetakan kaca hingga menutupi seluruh bagian dari serat tapis kelapa tersebut.

- Cetakan kaca ditutup dengan memakai cetakan kaca bagian atas yang telah terlebih dahulu dilapisin gliserin.

- Tutup dengan perlahan-lahan, arahkan void yang tedapat pada cetakan agar keluar dari cetakan tersebut dengan cara cetakan kaca bagian atas tadi ditekan secara perlahan-lahan hingga void dapat diarahkan keluar dari cetakan kaca tersebut.
- Berikan beban pada cetakan kaca bagian atas, dengan maksud agar komposit dapat terbentuk dengan baik dan sempurna.

- Setelah 24 jam atau setelah komposit kering, lepaskan beban dari cetakan bagian atas dan lepaskan komposit dari cetakan kaca tersebut

- Selanjutnya komposit berpenguat serat tapis kelapa telah siap untuk dijadikan spesimen uji lentur.

- Proses Post Curing. Komposit dimasukkan ke dalam oven dengan temperatur $65{ }^{\circ} \mathrm{C}$ selama 2 jam ${ }^{[2]}$. Tujuannya untuk menghilangkan gelembung-gelembung udara dan uap air yang terperangkap pada komposit, untuk mempercepat proses pengeringan pada komposit dan untuk mengetahui apakah komposit sudah homogen yaitu jika lembaran komposit tidak melengkung.

- Komposit yang berhasil dicetak, diamati apakah ada void atau tidak dengan cara menerawang lembaran komposit.

- Komposit yang berhasil dicetak diamati kelengkungannya, dengan cara manual. Dengan meletakkan lembaran komposit diatas lembaran kaca, lembaran komposit dinyatakan layak pakai untuk spesimen uji apabila seluruh permukaan lembaran komposit menyentuh dengan baik pada lembaran kaca tersebut.

- Spesimen uji impact dibuat sesuai dengan standar ASTM D- 256 ${ }^{[4]}$

- Spesimen yang sudah terbentuk dilakukan pengujian impact.

\section{Skematik Alat Uji Impact (Charpy Type) dan Alat Cetakan}

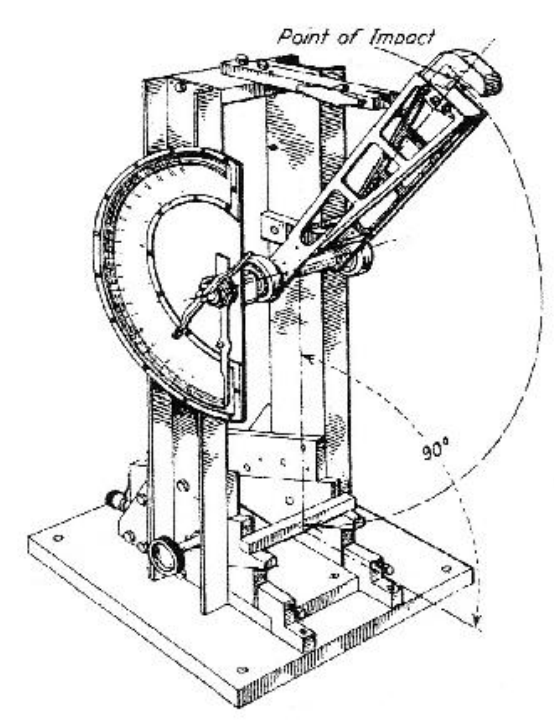

Gambar 2.1 Skema Alat Uji Impact (Charpy Type) 


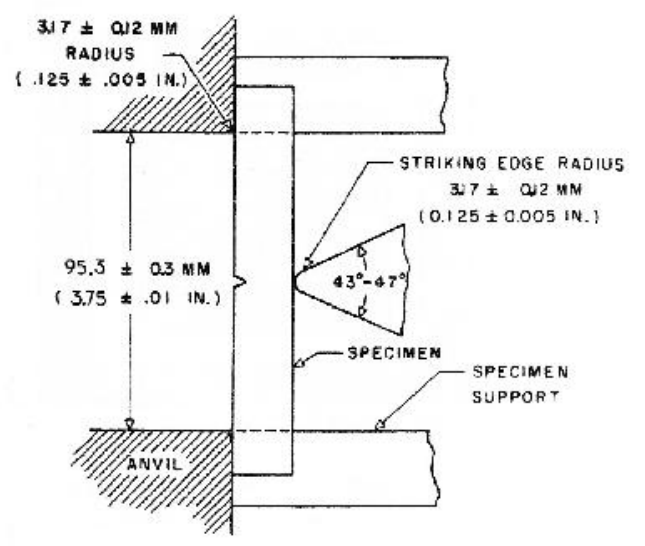

Gambar 2.2 Kedudukan Spesimen Uji pada alat Uji

\section{Skematik Alat Cetak Komposit}

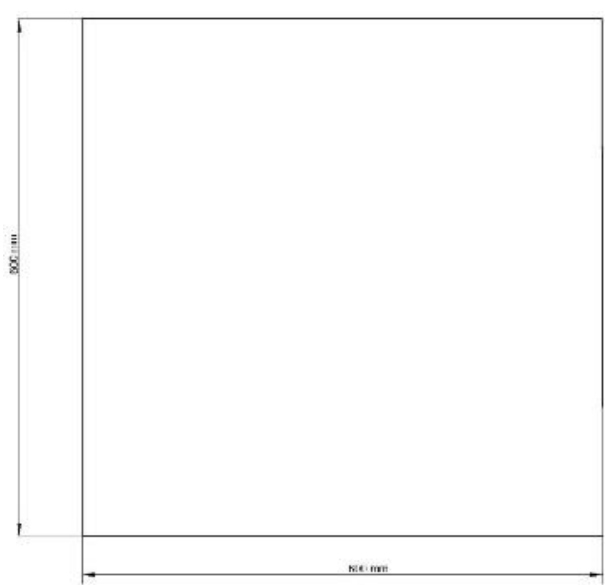

Lapisan bagian Atas dan Bawah
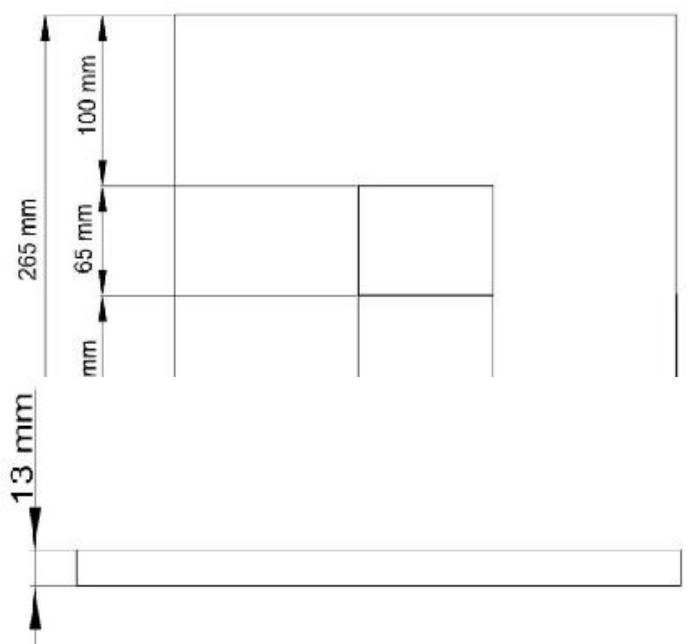

Cetakan Tengah

Gambar 2.3 Alat Cetak Teknik Press Hand Lay-Up 


\section{HASIL DAN PEMBAHASAN}

\subsection{Hasil Pengujian Uji Impact}

Tabel 3.1 Kekuatan Impact Komposit (N.m)

\begin{tabular}{|c|c|c|c|}
\hline \multirow{2}{*}{$\begin{array}{c}\text { Perlakuan Serat } \\
\text { NaOH }\end{array}$} & \multicolumn{3}{|c|}{ Fraksi Volume } \\
\hline & $20 \%$ & $25 \%$ & $30 \%$ \\
\hline \multirow{5}{*}{$\begin{array}{c}\text { Panjang Serat } \\
5 \mathrm{~mm}\end{array}$} & 0.007777550 & 0.015500031 & 0.015487836 \\
\hline & 0.011627321 & 0.015487836 & 0.011631911 \\
\hline & 0.007779092 & 0.015484790 & 0.011625023 \\
\hline & 0.011625023 & 0.011636476 & 0.023227185 \\
\hline & 0.015472607 & 0.011634184 & 0.015487836 \\
\hline Rata-rata & 0.010856319 & 0.013948663 & 0.015491958 \\
\hline \multirow{5}{*}{$\begin{array}{c}\text { Panjang Serat } \\
10 \mathrm{~mm}\end{array}$} & 0.011645646 & 0.027098383 & 0.015515302 \\
\hline & 0.011634184 & 0.011634184 & 0.023231754 \\
\hline & 0.019359795 & 0.015500031 & 0.023231754 \\
\hline & 0.015484790 & 0.019359795 & 0.023227185 \\
\hline & 0.015496992 & 0.015496992 & 0.015527528 \\
\hline Rata-rata & 0.014724282 & $\mathbf{0 . 0 1 7 8 1 7 8 7 7}$ & 0.020146705 \\
\hline \multirow{5}{*}{$\begin{array}{c}\text { Panjang Serat } \\
15 \mathrm{~mm}\end{array}$} & 0.019359795 & 0.027098383 & 0.027103713 \\
\hline & 0.023231754 & 0.011636476 & 0.027125054 \\
\hline & 0.011636476 & 0.027103713 & 0.030969580 \\
\hline & 0.015503095 & 0.027077062 & 0.019378869 \\
\hline & 0.023227185 & 0.023250047 & 0.023250047 \\
\hline Rata-rata & 0.018591661 & 0.023233136 & $\mathbf{0 . 0 2 5 5 6 5 4 5 2}$ \\
\hline
\end{tabular}

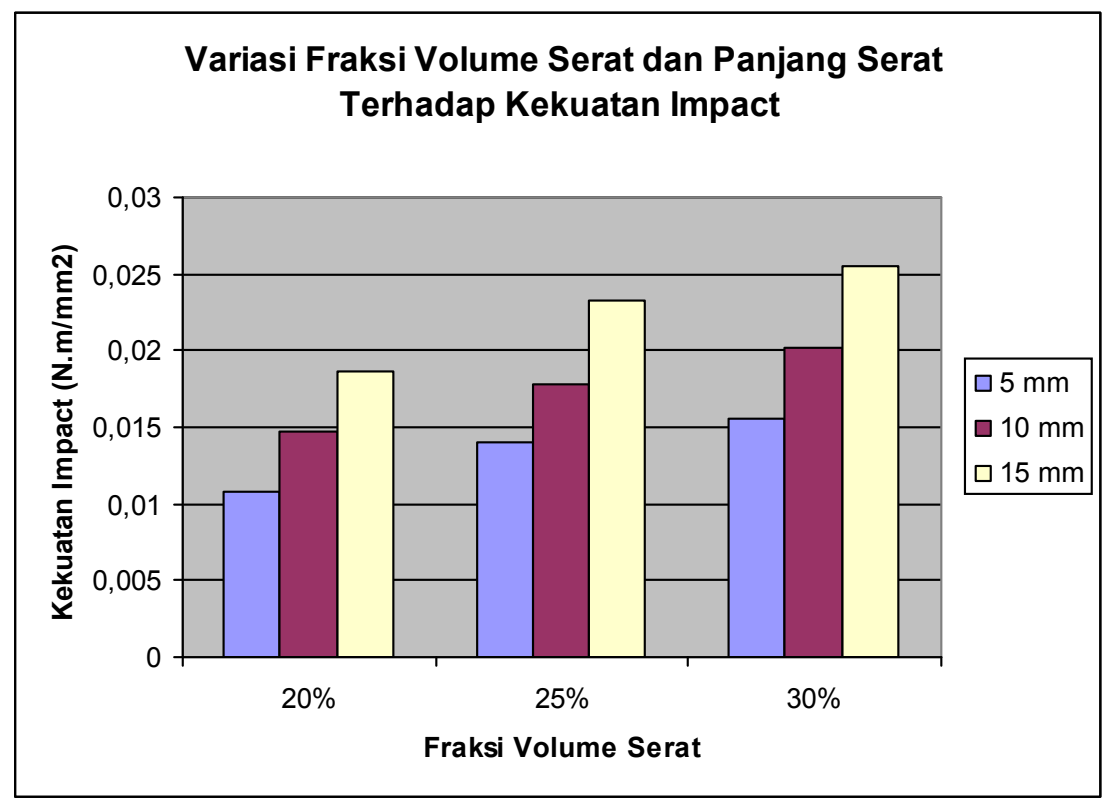

Grafik 3.1. Pengaruh Variasi Fraksi Volume dan Panjang Serat Terhadap Kekuatan Impact 


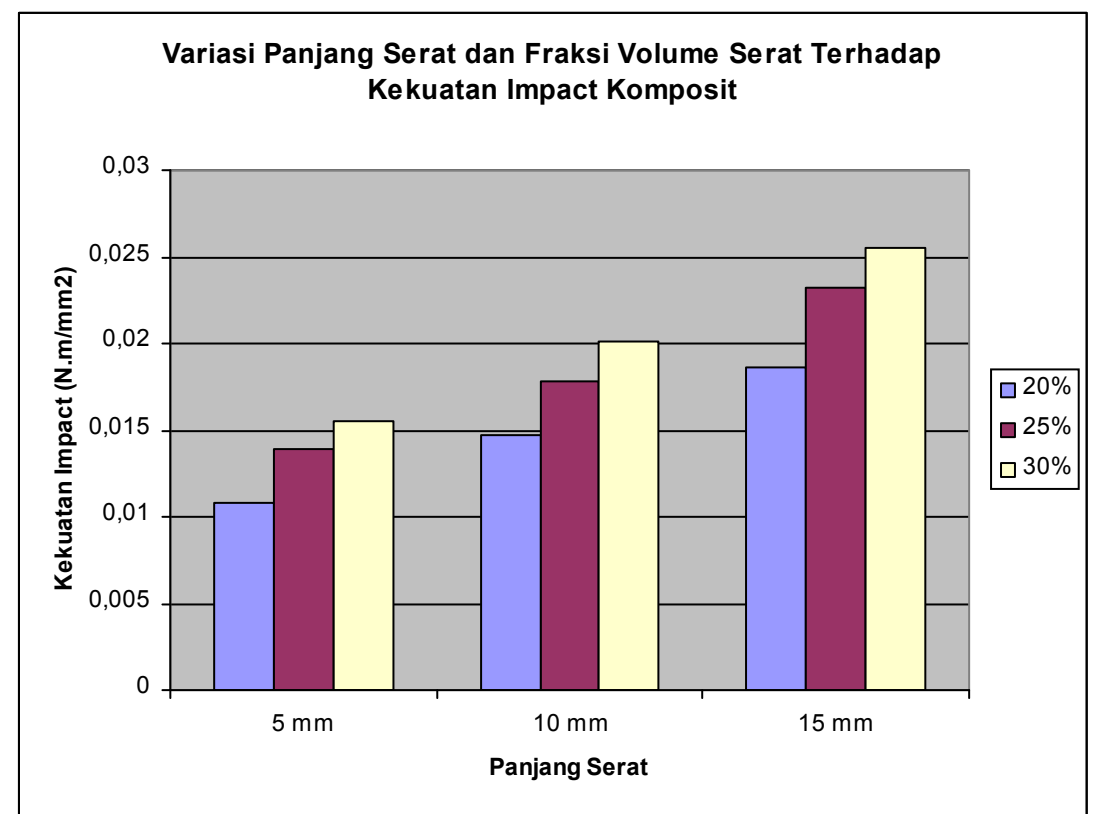

Grafik 3.2. Pengaruh Variasi Panjang Serat dan Fraksi Volume Terhadap Kekuatan Impact

\subsection{Pembahasan Uji Impact}

Berdasarkan Grafik 3.1 dapat terlihat bahwa hubungan antara panjang serat terhadap kekuatan impact mengalamai peningkatan, dimana kekuatan impact tertinggi terdapat pada panjang serat $15 \mathrm{~mm}$ dan kekuatan impact terkecil terdapat pada panjang serat $5 \mathrm{~mm}$. Dalam gambar 3.2 terlihat juga hubungan antara fraksi volume terhadap kekuatan impact mengalami peningkatan, dimana kekuatan impact tertinggi didapat pada fraksi volume $30 \%$ dan nilai kekuatan impact terkecil didapat pada fraksi volume $20 \%$.

Dari Grafik 3.2 menunjukkan hubungan antara panjang serat dan fraksi volume terhadap

\subsection{Pembahasan Foto Mikro}

Berdasarkan Gambar 3.3 terdapat interaksi antara matrik dan serat masih cukup besar berpengaruh terhadap kekuatan impact komposit serat tapis kelapa. dimana terlihat pullout yang disebabkan kerapuhan matrik yang menyebabkan serat terlepas, rapuhnya matrik disebabkan campuran resin dan catalis kurang sempurna dan pada saat pengadukan yang kurang merata, serta terdapatnya void. dan terlihat juga guratan-guratan matrik (matriks flow) yang masih banyak pada permukaan patahan yang memiliki pengaruh juga terhadap kekuatan impact komposit tersebut. dan terdapat crack deflection yang disebabkan karena posisi serat pada permukaan patahan miring mengikuti daerah patahan.

Pada Gambar 3.4 terdapat perbedaan dimana komposit dengan panjang serat $5 \mathrm{~mm}$ dengan fraksi kekuatan impact mengalami peningkatan dari variasi panjang serat $5 \mathrm{~mm}, 10 \mathrm{~mm}, 15 \mathrm{~mm}$ dan fraksi volume $20 \%, 25 \%, 30 \%$. Dari Pengujian dan perhitungan data maka didapatkan nilai kekuatan impact tertinggi pada komposit dengan panjang serat $15 \mathrm{~mm}$ dengan fraksi volume $30 \%$ sebesar $0.0255 \mathrm{Nm} / \mathrm{mm}^{2}$ Sedangkan panjang serat $5 \mathrm{~mm}$ dengan fraksi volume $20 \%$ didapat nilai kekuatan impact terkecil sebesar $0.0108 \mathrm{Nm} / \mathrm{mm}^{2}$, dan nilai kekuatan impact dengan panjang serat $10 \mathrm{~mm}$ dengan fraksi volume $30 \%$ sebesar 0.0201 $\mathrm{Nm} / \mathrm{mm}^{2}$.

$30 \%$ permukaan patahannya tampak lebih gelap yang artinya sudah semakin sedikit terjadinya interaksi antara serat dan matrik terhadap pembebanan pada uji impact, walaupun masih terlihat ada pullout dan matrik flow yang terjadi, kecil pengaruhnya karena jumlah serat dan luas permukaan retakan sudah mengecil.

Pada Gambar 3.3 pada komposit dengan kekuatan impact terkecil di daerah patahan terlihat juga partikel-partikel kecil yang menempel pada matrik yang berbentuk seperti pecahan-pecahan kecil, ini diakibatkan karena di daerah yang mengalami pecahan-pecahan kecil masih kebayankan catalis yang disebabkan kurang merata campuran dan saat pengadukan antara resin dengan catalis. Sedangkan pada gambar 3.4 terlihat partikel-partikel tersebut sudah sedikit. 


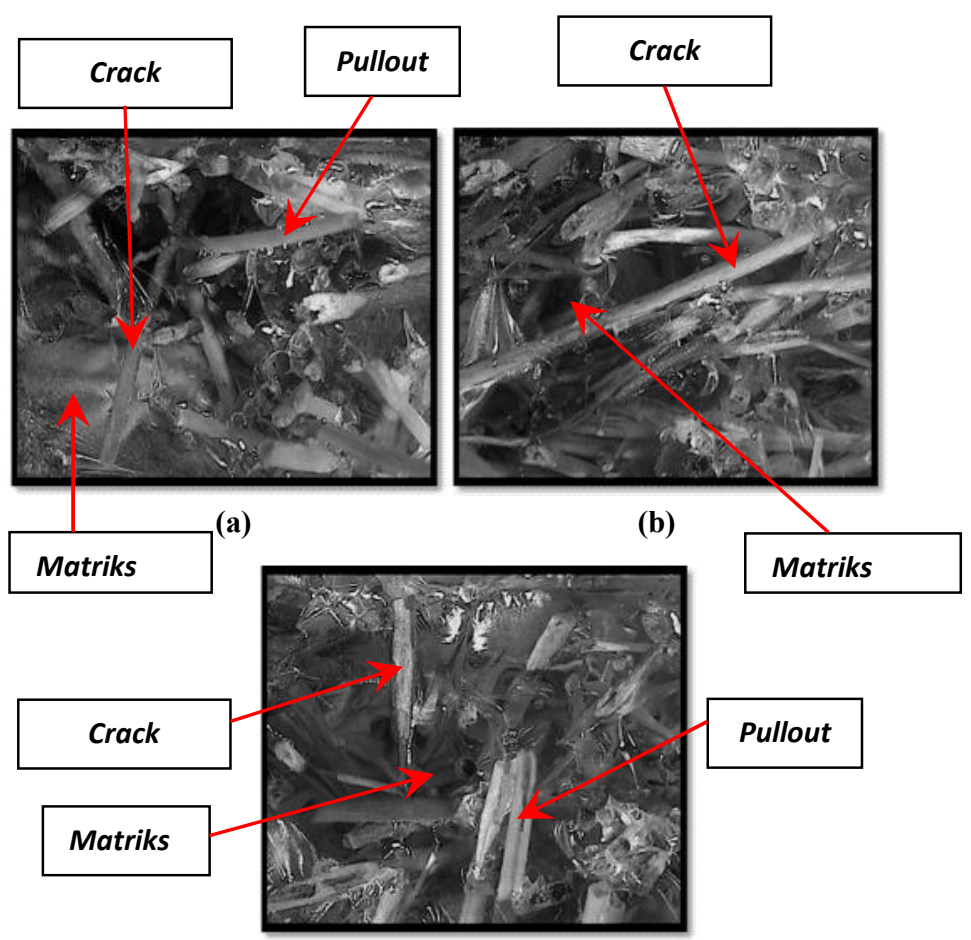

(c)

Ganbar 3.3 Foto Mikro pada komposit fraksi volume $20 \%$ dengan pembesaran 10x pada stereo microscope a). Panjang serat $5 \mathrm{~mm}$, b). Panjang serat $10 \mathrm{~mm}, \mathrm{c})$. Panjang serat $15 \mathrm{~mm}$

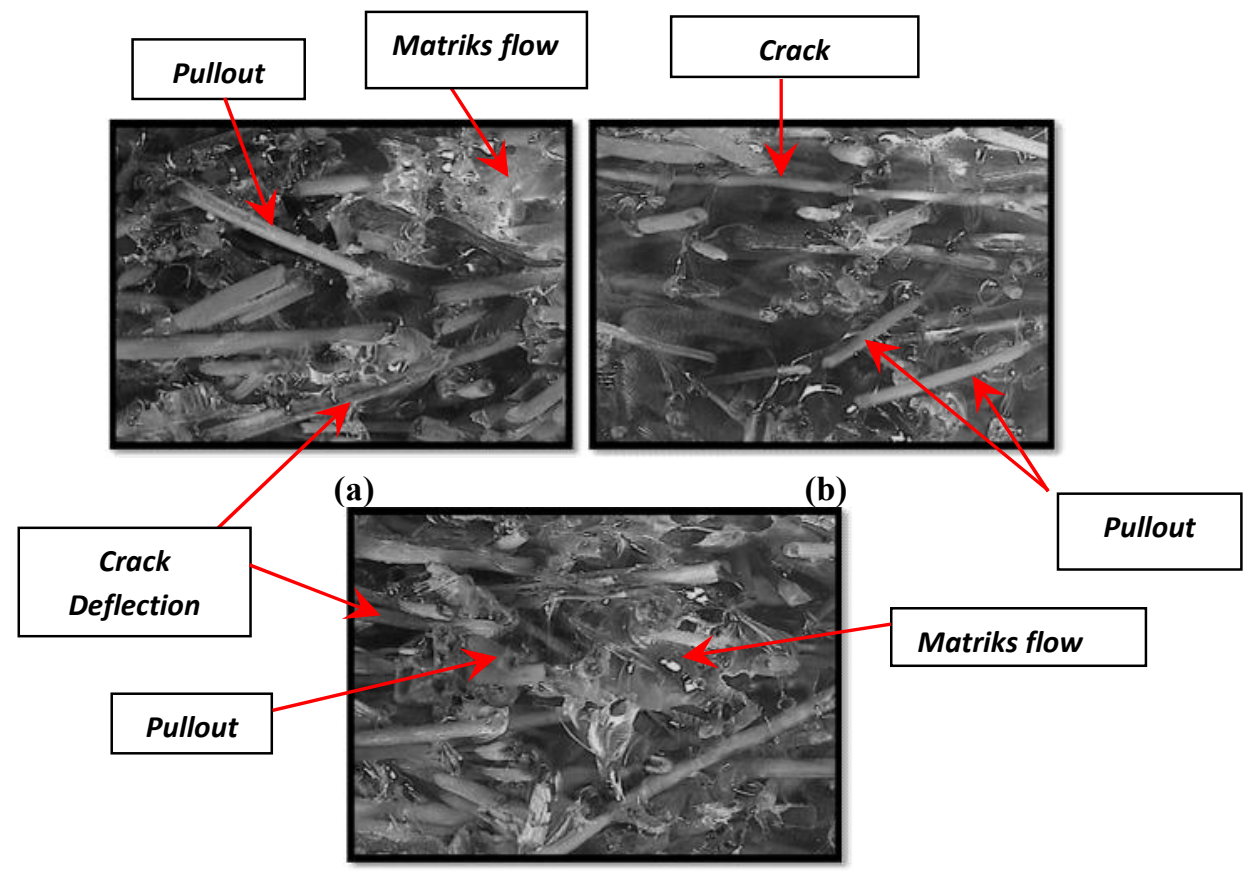

(c)

Gambar 3.4 Foto Mikro pada komposit fraksi volume 30\% dengan pembesaran 10x pada stereo microscope a). Panjang serat $5 \mathrm{~mm}$, b). Panjang serat $10 \mathrm{~mm}, \mathrm{c})$. Panjang serat $15 \mathrm{~mm}$ 


\section{KESIMPULAN}

\subsection{Kesimpulan}

Dari hasil penelitian dan pembahasan pada bab-bab sebelumnya dapat diambil beberapa kesimpulan sebagai berikut :

1. Kekuatan impact meningkat seiring meningkatnya fraksi volume dan panjang serat. Nilai kekuatan impact terbesar terdapat pada pengujian impact dengan komposit panjang serat $15 \mathrm{~mm}$ dengan Fraksi Volume $30 \%$ sebesar 0.0255 $\mathrm{Nm} / \mathrm{mm}^{2}$

2. Hasil pengamatan struktur mikro menunjukkan bahwa pada panjang serat $15 \mathrm{~mm}$ ikatan antara matrik dan serat lebih kuat dibandingkan dengan variasi panjang serat $5 \mathrm{~mm}$ dan $10 \mathrm{~mm}$ sehingga komposit yang dihasilkan lebih kuat dan mempunyai nilai kekuatan impact yang

\section{DAFTAR PUSTAKA}

[1] Suardana, N P G, Dwidiani Ni Made, (2007), Analisa Kekuatan Tarik Dan Lentur Komposit Polyester Serat Tapis Kelapa Orientasi Acak Dengan Variasi Waktu Perlakuan $\mathrm{NaOH}$.

[2] Suardana, N.P.G, Cok Putri (2007), Pengaruh Perendaman Air Terhadap Sifat Mekanis Komposit Serat Tapis Kelapa Dengan Orientasi Acak.

[3] ASTM ( 2003 ) D 256 Standard Test Methods for Void Content of Reinforced Plastics. ASTM Internasional, USA.

[4] Jamasri, Diharjo, K, Handiko, G. W. (2005), Studi Perlakuan Alkali Terhadap Sifat Tarik Komposit Limbah Serat Sawit - Polyester, Prosiding Seminar Nasional Tahunan Teknik Mesin IV, Universitas Udayana, Bali.

[5] Lokantara Putu, Suardana, N P G, (2007), Analisis Arah dan Perlakuan Serat Tapis Serta Rasio Epoxy Hardener Terhadap Sifat Fisis dan Mekanis Komposit Tapis/Epoxy, Jurnal Ilmiah Teknik Mesin Cakram Vol. 1 No. $1,(15-21)$. lebih besar. Semakin panjang serat yang digunakan akan mengurangi crack deflection sehingga kekuatan impact menjadi semakin baik. Demikian pula dengan fraksi volume yang semakin tinggi menyebabkan matrix flow berkurang sehingga kekuatan impact akan meningkat.

\subsection{Saran}

Diharapkan pada penelitian selanjutnya dilakukan pencetakan dengan fraksi volume yang lebih besar yaitu diatas $30 \%$ seperti 35\%, 40\% ataupun 50\%. Sehingga dapat diketahui kondisi optimum dari fraksi volume serat yang menghasilkan kekuatan impact maksimum.

[6] Mohan Rao, K.M., and Mohana Rao, K., (2005), Extraction and tensile properties of natural fibers : Vakka, date and bamboo, Elsevier, Composite structures.

[7] Oksman, K., Skrifvars, M., Selin, J-F., (2003), Natural Fiber as Reinforcement in Polylactic Acid (PLA) Composites, Composites Science and Technology 63, Sciencedirect.com, 13171324.

[8] Suardia, T, Saito, S. (1985). Ilmu Pengetahuan Bahan Teknik, Pradnya Paramita Jakarta.

[9] Satyanarayana, K. G., dkk (1982), Structure Property Studies of Fibres From Various Parts of The Coconut Tree. Journal of Material Science 17, India

[10] Taurista, A.Y, Riani, A.O, Putra, K.H. (2003), Komposit Laminat Bambu Serat Woven Sebagai Bahan Alternatif Pengganti Fiber Glass Pada Kulit Kapal. ITS, Surabaya..

[11] Wr Wijang, Ariawan Dody, (2006), Pengaruh Modifikasi Serat Terhadap Karakteristik Komposit UPRs - Cantula, Jurnal Teknik Mesin Poros Volume 9 Nomer 3, ( 200-206 ). 